\title{
Inflation Control: Do Central Bankers Have It Right?
}

Stephen Williamson

Neo-Fisherites argue that conventional central banking wisdom has inflation control wrong, in that the way to increase (reduce) inflation is to increase (reduce) the central bank's nominal interest rate target. This article shows how two conventional macroeconomic monetary models-a New Keynesian (NK) model and a segmented markets model-exhibit neo-Fisherian properties. Thus, neo-Fisherism should actually be the foundation for conventional inflation control. (JEL E4, E5)

Federal Reserve Bank of St. Louis Review, Second Quarter 2018, 100(2), pp. 127-50.

https://doi.org/10.20955/r.2018.127-50

A ccording to conventional wisdom, central banks should control inflation by increasing the central bank's nominal interest rate target when inflation is above target and by decreasing the nominal interest rate when inflation is too low. But neo-Fisherites argue that the reverse is true. For example, a central bank that sees chronically low inflation has no choice but to increase its nominal interest rate target, which will cause inflation to go up, according to neo-Fisherian doctrine.

The purpose of this article is to explore the properties of two standard macroeconomic monetary models—a New Keynesian (NK) model and a segmented markets model—and show how these conventional models exhibit neo-Fisherian properties. Thus, neo-Fisherism is not about some outlandish, radical new macroeconomic theory. In fact, conventional wisdom is somewhat hard to come by in what are considered conventional macroeconomic models, in that the conventional results (lower inflation resulting from a higher nominal interest rate target) require some specific, and perhaps extreme, assumptions.

It might seem surprising now, but before the 1980s many prominent economists did not subscribe to the view that the job of controlling inflation resides solely with the central bank. Indeed, at a time of relatively high inflation in the United States in 1980, James Tobin (1980), an influential macroeconomist at Yale University, argued that "it is not possible to do the job

Stephen Williamson is a visiting scholar at the Federal Reserve Bank of St. Louis and a professor of economics and the Stephen A. Jarislowsky Chair in Central Banking at the University of Western Ontario. He was a vice president and economist at the Federal Reserve Bank of St. Louis and editor-in-chief of Review.

C 2018, Federal Reserve Bank of St. Louis. The views expressed in this article are those of the author(s) and do not necessarily reflect the views of the Federal Reserve System, the Board of Governors, or the regional Federal Reserve Banks. Articles may be reprinted, reproduced, published, distributed, displayed, and transmitted in their entirety if copyright notice, author name(s), and full citation are included. Abstracts, synopses, and other derivative works may be made only with prior written permission of the Federal Reserve Bank of St. Louis. 
[disinflation] without effective wage and price controls of some kind...there could be worse prospects, and probably they include determined but unassisted monetary disinflation."

At the time, it was widely recognized that inflation was too high and that there would be economic benefits from reducing the inflation rate. Tobin argued that monetary disinflation-a reduction in inflation to appropriate levels engineered solely by the central bank-would be far too costly; disinflation would require a period of above-normal unemployment lasting more than 10 years. These economic costs of disinflation could, and should, be mitigated through wage and price controls, according to Tobin.

Of course, policymakers in the United States did not follow Tobin's advice, and his dire predictions did not come to pass. During Paul Volcker's term as Federal Reserve Chair, an unassisted monetary disinflation in fact occurred, with the inflation rate (consumer price index inflation) falling from a peak of 14.4 percent in May 1980 to 3.6 percent in 1985. The 1981-82 recession, often attributed to the monetary disinflation, was severe but short, particularly relative to what Tobin had imagined.

Volcker's disinflationary experiment was compelling, and this pushed monetarist ideas into the forefront at central banks. The most prominent proponent of monetarism (sometimes known as the quantity theory of money) was Milton Friedman. Friedman (1968) argued that an optimal monetary policy would involve targeting the growth rate in some measure of the money supply. Such a policy, according to Friedman, would make the inflation rate stable and predictable, and it would minimize the contribution of monetary disturbances to business cycles. Roughly, Volcker's disinflation was carried out following Friedman's prescriptionVolcker dramatically reduced the rate of money growth, and inflation came down.

But the move by many central banks to follow money growth targeting as a permanent policy did not meet with success, principally because of the unstable relationship between money and other macroeconomic variables that became even more unstable in the 1980s. In response to this environment, monetary policymakers in many countries, including the United States, adopted the following principles: (i) Inflation control should be the purview of the central bank-the surviving element of monetarism in modern monetary policy, and (ii) monetary policy should be implemented through the targeting of a short-term nominal interest rate, typically an overnight rate.

Usually, a central bank is given some guidelines on policy goals by the government. In some countries-New Zealand, Canada, and the United Kingdom, among others—-the government and the central bank agree to an inflation target, and then the central bank is left to its own devices in achieving that target. In the United States, Congress has specified a dual mandate, typically described as specifying that the Federal Reserve System pursue price stability and maximum employment. As yet, however, Congress has not been specific about the meaning of price stability and maximum employment or about the mechanisms for achieving these goals.

But once a central bank is committed to controlling inflation and does so by targeting a short-term nominal interest rate, how should observations about inflation translate into decisions about the interest rate target? John Taylor (1993) provided an answer in his seminal Taylor rule paper. According to Taylor, the central bank should respond to two economic variables: the current inflation rate and some measure of the output gap-the difference 
between the economically efficient level of aggregate economic activity and the actual level. Taylor argued that the nominal interest rate should increase (decrease) if the inflation rate is above (below) its target, and the nominal interest rate should decrease (increase) when the output gap is positive (negative). Further, according to what is now called the Taylor principle, a 1-percentage-point increase in the inflation rate should be met by a more-than-one-for-one increase in the nominal interest rate.

The Taylor rule has gained a strong foothold, both in monetary policy circles and in NK economics (Woodford, 2003). For example, here is how the Bank of Canada (2017) describes its monetary policy decisions: "If inflation is above target, the Bank may raise the policy rate. Doing so encourages financial institutions to increase interest rates on their loans and mortgages, discouraging borrowing and spending and thereby easing the upward pressure on prices."

This is basically Taylor rule logic, and it incorporates another element of conventional central banking wisdom: the Phillips curve. According to Phillips curve thinking, inflation is caused by movements in real output-more spending and higher output implies higher inflation, and less spending and lower output implies lower inflation. Janet Yellen (2017), like other central bankers in the world, has made statements that reflect Phillips curve thinking: For example, "when the economy is threatening to push inflation too high down the road, we increase interest rates to keep the economy on a sustainable path and lean against its tendency to boom and then bust."

But, for the past 45 years or more, economists have had doubts about the usefulness of the Phillips curve as a component in the framework of inflation control. Most recently, Lawrence Summers (2017) has argued that "economists should now have great humility regarding the inflation process. The Phillips curve relation on which they have relied has largely broken down over the past several decades."

A more radical view is that central bankers are more than a little confused about the details of the inflation mechanism. Neo-Fisherites argue that if inflation is too low, then central banks can increase it by increasing the target for the nominal interest rate. It is widely understood that in the long run, inflation and nominal interest rates are positively correlated. Typically, this is explained as arising from the Fisher effect, named after Irving Fisher, whereby higher inflation increases nominal interest rates through an inflation premium effect. Neo-Fisherism turns this idea on its head, in that higher nominal interest rates act to cause higher inflation, even in the short run.

Plenty of empirical support for neo-Fisherism can be found in the data, as pointed out in Williamson (2016). In addition to the strong positive correlation observed between inflation and nominal interest rates, countries in which nominal interest rates have been low for a long period of time tend to exhibit persistently low inflation. In particular, in Japan the nominal interest rates have been very low for more than 20 years now-a period over which the average rate of inflation was about zero. Further, despite the fact that NK economics is often cited as supportive of standard central banking practice, some writers have pointed out that NK models actually have neo-Fisherian properties (Cochrane, 2016, and Rupert and Sustek, 2016). This is perhaps surprising, as NK models incorporate elements, including sticky prices and a Phillips curve mechanism, that are part of the standard central banking narrative. 
The goal of this article is to show how some standard macroeconomic models have neoFisherian properties, why they have those properties, and what assumptions it takes to deliver theoretical results that conform to standard central bank thinking. The key results are that NK models exhibit low-inflation policy traps; these models have the property that higher nominal interest rates make inflation go up; and neo-Fisherian monetary policy rules work well in NK models to achieve central bank inflation goals. We also show that these results are not particular to NK models and hold in segmented markets models of monetary economies as well.

In NK models, as pointed out initially by Benhabib, Schmitt-Grohe, and Uribe (2001) and stressed by Bullard (2010) and Andolfatto and Williamson (2015), a central bank following the Taylor principle can lead itself into a low-inflation policy trap. That is, given the policy rule, there are many equilibria that converge to a steady state in which the nominal interest rate is zero and inflation is below the central bank's target. The central bank persists in keeping the nominal interest rate low, expecting that inflation will go up, but this never happens. This is an apt description of how many central banks have behaved in the face of persistently low inflation. We show that the cure for the low-inflation policy trap is a neo-Fisherian policy under which the central bank raises the nominal interest rate in response to low current inflation, and it raises rates to choke off incipient future inflation in excess of the inflation target. Conventional central banking wisdom holds in our NK model if inflation expectations and prices are sufficiently sticky, but then the model is inconsistent with experience-the Japanese experience in particular.

Essentially, all macroeconomic monetary models exhibit a long-run Fisher effect: If the nominal interest rate goes up, then, in the long run, inflation increases. The Fisher effect is one-for-one in models in which the real interest rate is invariant to monetary policy in the long run. So it is necessary in the short run that there be another effect-a liquidity effectthat opposes the Fisher effect, if inflation is to fall in the short run when the central bank raises the nominal interest rate. Standard NK models do exhibit a liquidity effect, which works through sticky prices. But in our NK model, this liquidity effect is not large enough to offset the Fisher effect, unless inflation expectations and prices are sufficiently sticky. However, what about other models of the liquidity effect? Maybe those models can have strong enough liquidity effects to offset the Fisher effect in the short run?

Originating with the work of Grossman and Weiss (1983) and Rotemberg (1984), a large body of literature exists that studies the properties of segmented markets models. This work also includes Lucas (1990), Alvarez, Lucas, and Weber (2001), and Alvarez, Atkeson, and Kehoe (2002). We explore the behavior of a version of Alvarez, Lucas, and Weber (2001) and find that it has essentially the same inflation dynamics as our NK model: A low-inflation policy trap exists; increases in nominal interest rates raise inflation in the short run; and neo-Fisherian policy rules work well.

This article proceeds as follows. In the second section, a simple NK model is constructed, and it is shown how this model behaves if the nominal interest rate is constant forever, if the nominal interest rate goes up, if the central bank follows a Taylor rule or a neo-Fisherian rule, and if expectations are sticky. In the third section, a segmented markets model is constructed, which is shown to have properties similar to the NK model. The final section concludes. 


\section{A NEW KEYNESIAN MODEL}

We will first work with an NK model to study the inflation dynamics that arise under alternative monetary policy rules. In this context, we define good performance for a monetary policy rule as behavior for the inflation rate that comes as close as possible to hitting the central bank's inflation target. We will study how the model behaves under rational expectations and with sticky inflation expectations. To show that our results are not peculiar to NK models, we explore the properties of an alternative model in the next section.

Basic NK models (see, e.g., Woodford, 2003) are extensions of standard neoclassical growth models, of the kind used in the real business cycle literature (see Prescott, 1986, or Cooley, 1995 ) to explain how business cycles can arise from exogenous technology shocks. But in NK models, the idea is to extend such frameworks so that they can be used in formulating monetary policy, by including sticky prices and/or sticky wages and a role for the central bank.

We will start with a simplified NK model. To focus on how inflation is determined, assume there is no aggregate uncertainty. In this economy, the representative consumer maximizes

$$
\sum_{t=0}^{\infty}\left(\frac{1}{1+r}\right)^{t}\left[\frac{C_{t}^{1-\alpha}-1}{1-\alpha}-v\left(N_{t}\right)\right],
$$

where $r$ is the subjective discount rate, $C_{t}$ is consumption, and $N_{t}$ is labor supply. Assume that $v(\cdot)$ is strictly convex; that is, the marginal disutility from supplying labor increases as more labor is supplied. For convenience, we have assumed that the utility from consumption for the representative consumer has the property such that the coefficient of relative risk aversion is a constant, $\alpha>0$.

In this economy, there is a one-period bond for which the purchase price is one unit of money in period $t$, and this bond pays off $1+S_{t}$ units of money in period $t+1$. Then, standard asset pricing implies that $S_{t}$ must satisfy

$$
-C_{t}^{-\alpha}+\frac{C_{t+1}^{-\alpha}\left(1+S_{t}\right)}{(1+r)\left(1+i_{t+1}\right)}=0
$$

Equation (2) states that the net marginal payoff for the representative consumer to holding the one-period bond must be zero in equilibrium. At the margin, if the consumer gives up one unit of consumption in period $t$ to purchase bonds, then the loss is the marginal utility of consumption for the consumer, $C_{t}^{-\alpha}$. At the margin, the gain is the future marginal utility of consumption, discounted, multiplied by the payoff on the asset in units of future consumption, which is $\frac{1+S_{t}}{1+i_{t+1}}$, where $i_{t+1}$ is the inflation rate between period $t$ and period $t+1$.

We will assume that there is no capital in this economy and no international trade, so $C_{t}=Y_{t}$ in equilibrium, where $Y_{t}$ denotes total aggregate output. That is, all output must be consumed in equilibrium. Leaving out the details of production, let $\hat{Y}$ denote the economically efficient level of output so that $Y_{t} / \hat{Y}$ is a measure of the output gap. Then, substituting in equation (2) for consumption, taking natural logs, and rearranging, we obtain 


$$
y_{t}=y_{t+1}-\frac{1}{\alpha}\left(R_{t}-\pi_{t+1}-\rho\right) .
$$

In equation (3), $y_{t}=\log \left(\frac{Y_{t}}{\hat{Y}}\right), R_{t}=\log \left(1+S_{t}\right), \rho=\log (1+r)$, and $\pi_{t+1}=\log \left(1+i_{t+1}\right)$. Thus, equation (3) is an NK "IS curve," which states that the current output gap increases as the future output gap increases, and it decreases with the difference between the real interest rate $R_{t}-\pi_{t+1}$ and the "natural real interest rate" $\rho$.

The Phillips curve in NK models is derived from the behavior of forward-looking price-setting firms and would typically be expressed (see Woodford, 2003) in this context as

$$
\pi_{t}=\gamma y_{t}+\beta \pi_{t+1} \text {, }
$$

where $\gamma>0$ and $0<\beta<1$. Thus, current inflation increases with the output gap and anticipated future inflation. For our purposes, it is easier to show our arguments if we assume that $\beta=0$. This will not cause any serious harm. Then, we can write the Phillips curve as

$$
\pi_{t}=\gamma y_{t}
$$

where $\gamma>0$ denotes the degree of price stickiness (higher $\gamma$ implies less price stickiness). Indeed, in the model constructed in Williamson (2017), which uses a somewhat different version of sticky prices than the Calvo pricing mechanism commonly used in NK models, a Phillips curve in the form of equation (5) is derived. See also Kocherlakota (2016).

As in typical NK models, we assume that the central bank has the power to set $R_{t}$ the nominal interest rate. That is, most NK models are silent about the apparatus (open market operations, interest payments on reserves, corridor system vs. floor system, etc.) that the central bank uses to target interest rates. Assuming it is possible for the central bank to dictate the market nominal interest rate, a standard approach to policy in NK models is to have the central bank follow a Taylor rule (as in Taylor, 1993). With a typical Taylor rule, the central bank sets the current nominal interest rate based on observed inflation and the output gap. For convenience, as we want to focus on implications for inflation control, we will leave out the term in the output gap and express the Taylor rule as

$$
R_{t}=\max \left[0, \rho+\delta \pi_{t}+(1-\delta) \pi^{*}\right] .
$$

In equation (6), $\delta$ is a parameter and $\pi^{*}$ denotes the central bank's inflation target. Note that we have accounted for the zero lower bound (ZLB) on the nominal interest rate. That is, if inflation is such that $\rho+\delta \pi_{t}+(1-\delta) \pi^{*}<0$, the central bank chooses $R_{t}=0$.

We now have a complete model consisting of an IS curve, equation (4); a Phillips curve, equation (5); and the Taylor rule, equation (6), that determines the output gap $y_{t}$, the inflation rate $\pi_{t}$, and the nominal interest rate $R_{t}$ in each period $t=0,1,2,3, \ldots$ 
Figure 1

Pegged Nominal Interest Rate

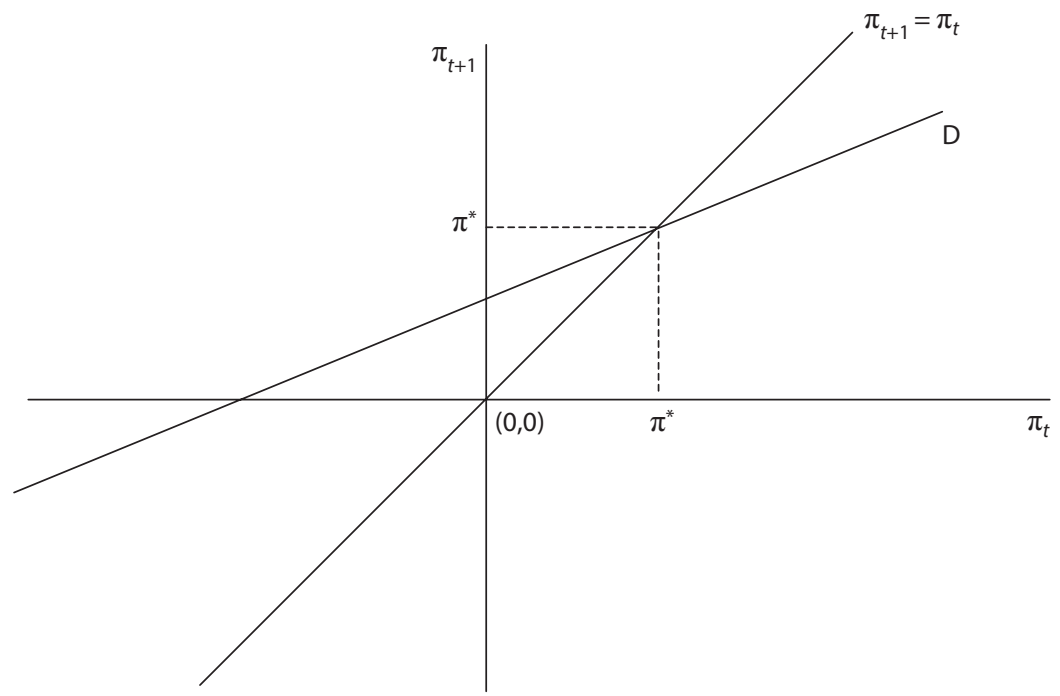

\section{Constant Nominal Interest Rate}

We will start by assuming rational expectations. Because there is no aggregate uncertainty in this context, this implies that the residents of this model economy correctly predict future variables in equilibrium. Our first exercise will consist of studying the properties of our model if the central bank pegs the nominal interest rate at some arbitrary value forever. This is potentially interesting, as a common view is that nominal interest rate pegs generate instability in the economy (see, e.g., Woodford, 2003). A constant nominal interest rate policy by the central bank implies that $\delta=0$ in the Taylor rule (6), so $R_{t}=\rho+\pi^{*}$, where we assume $\pi^{*} \geq-\rho$; that is, the interest rate peg does not violate the ZLB. Then, substituting in equation (4) for $y_{t+1}$ using equation (5), and for $R_{t}$ using equation (5), we obtain

$$
\pi_{t+1}=\frac{\gamma}{\alpha+\gamma} \pi^{*}+\frac{\alpha}{\alpha+\gamma} \pi_{t}
$$

Then, any path for inflation $\pi_{0}, \pi_{1}, \pi_{2}, \ldots$ that satisfies equation (7) is an equilibrium. Once we have determined an equilibrium path for the inflation rate, we can then determine the equilibrium path for output from equation (5). Equation (7) is a linear first-order difference equation in $\pi_{t}$, which is shown as $D$ in Figure 1 . The unique steady state is $\pi_{t}=\pi^{*}$, and in this steady state the central bank achieves its inflation target forever. From equation (5), equilibrium output in the steady state is $y_{t}=\frac{\pi^{*}}{\gamma}$ for all $t$.

But there are many other equilibria than the steady state. Indeed, we can choose any initial real number $\pi_{0}$ and then use equation (7) to solve for the equilibrium path. For example, in 
Figure 2

\section{A Dynamic Equilibrium}

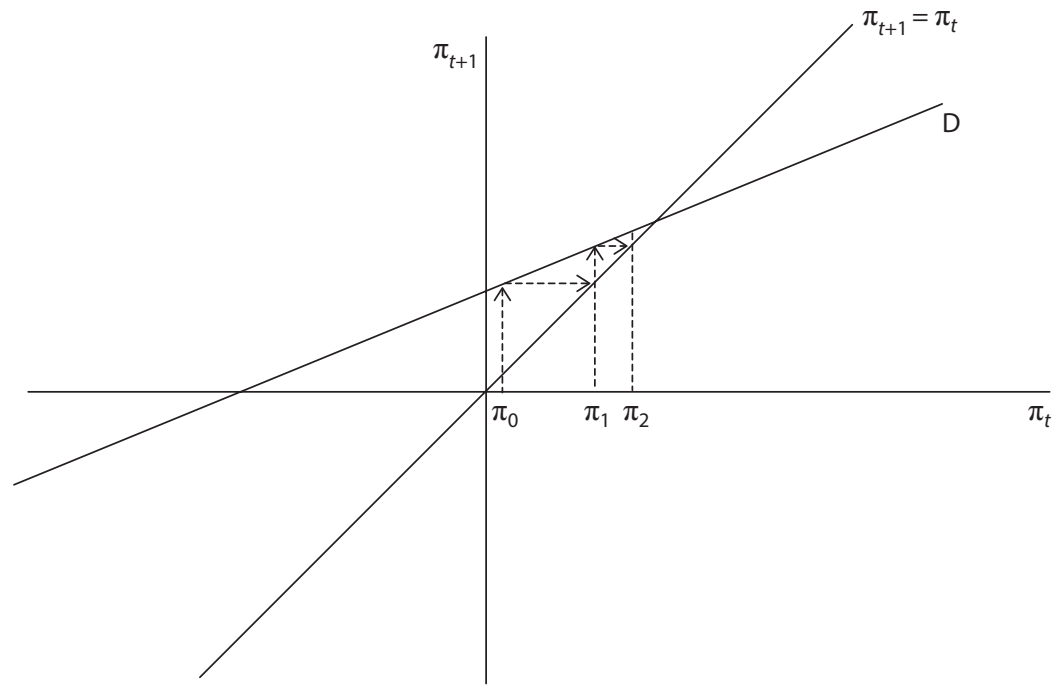

Figure 2 the path that begins at $\pi_{0}$ is an equilibrium path. All equilibria converge in the limit to the steady state in which the central bank achieves its inflation target because the slope of equation (7) is $\frac{\gamma}{\alpha+\gamma}$, which is greater than zero and less than one. Thus, an interest rate peg does not generate instability in this NK model. There is indeterminacy, as there are many equilibria, but all equilibria have the property that there is convergence to the central bank's inflation target in the long run. However, it is certainly not a virtue of the nominal interest rate peg that there is indeterminacy. The problem with multiple equilibria is that the model does not allow us to predict the effects of policy-many things can happen, and inflation could be very far from the inflation target for a very long time. Therefore, in this model there are virtues associated with a pegged nominal interest rate but some drawbacks as well.

\section{A Neo-Fisherian Experiment}

In conventional central banking thought, inflation is controlled by tightening when inflation is too high and by accommodating when inflation is too low. Typically for central bankers, tightening means that the nominal interest rate goes up, and accommodating means that the nominal interest rate goes down. But from equations (3) and (5), no matter what the monetary policy rule is, a steady state in which $R_{t}=R, y_{t}=y$, and $\pi_{t}=\pi$ forever, where $R, y$, and $\pi$ are constants, has the property that

$$
R=\rho+\pi,
$$

which is a version of the long-run Fisher equation. The long-run real interest rate, or natural real interest rate, in this model is a constant $\rho$, and in the steady state the nominal interest rate 
Figure 3

Increase in the Nominal Interest Rate

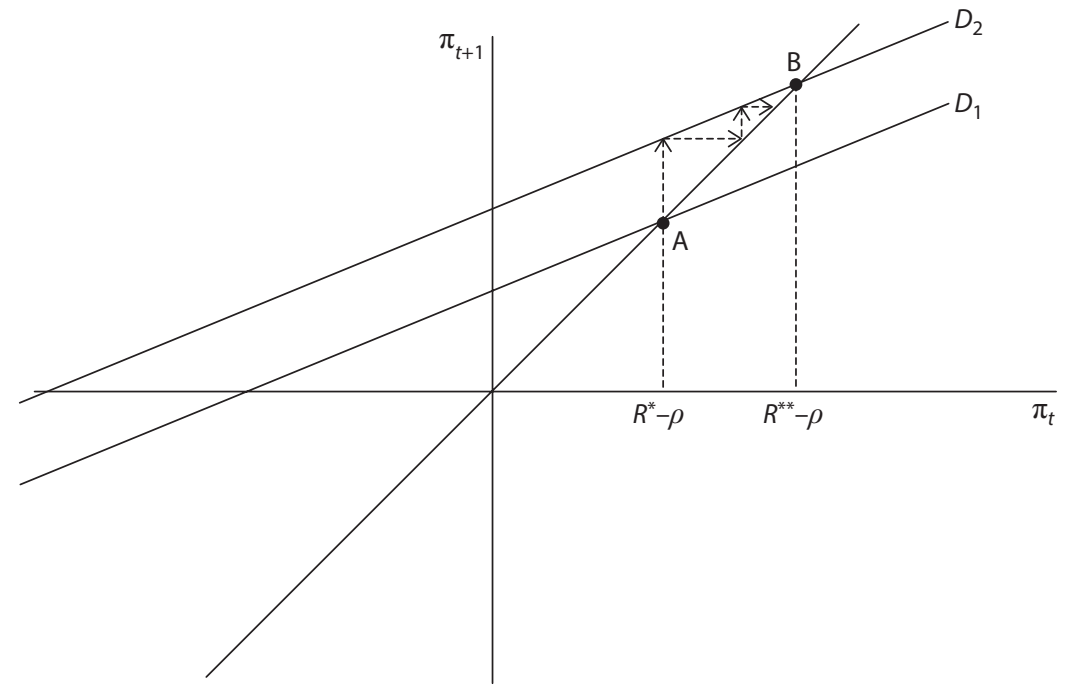

is the natural rate of interest plus the inflation rate. Therefore, a permanent increase in the nominal interest rate must lead to a permanent one-for-one increase in the inflation rate in the steady state. That is, if the central bank tightens, then the long-run inflation rate must go up, not down.

But central bankers are concerned with the short run as well as the long run. And Keynes had a point when he told us that "in the long run we are all dead" (Keynes, 1923). A phenomenon that monetary economists have explored is the short-run liquidity effect, one dimension of which is that it might be possible in the short run for the nominal interest rate and the inflation rate to move in opposite directions. For example, Lucas (1990) and Alvarez, Atkeson, and Kehoe (2002), among others, explored liquidity effects arising from market segmentation. In market segmentation models, one of which we will consider in the next section, an open market purchase of government bonds that leads to an increase in the money supply can cause the nominal interest rate to go down in the short run.

A widely held belief is that NK models exhibit strong liquidity effects. Standard intuition holds that, in such models, an increase in the nominal interest rate increases the real interest rate because expected inflation increases less than one-for-one in response to the nominal interest rate increase, as prices are sticky. This increase in the real interest rate reduces current spending and current aggregate output. Because output is lower, inflation is lower through a Phillips curve effect. Our model incorporates these elements: (i) The IS relationship (3) says that an increase in the real interest rate, given future output, will reduce current output; and (ii) the Phillips curve relationship (5) says that a reduction in output causes a reduction in inflation. So one might expect that the standard intuition holds in this NK model. 
Williamson

Figure 4

Responses to an Interest Rate Increase

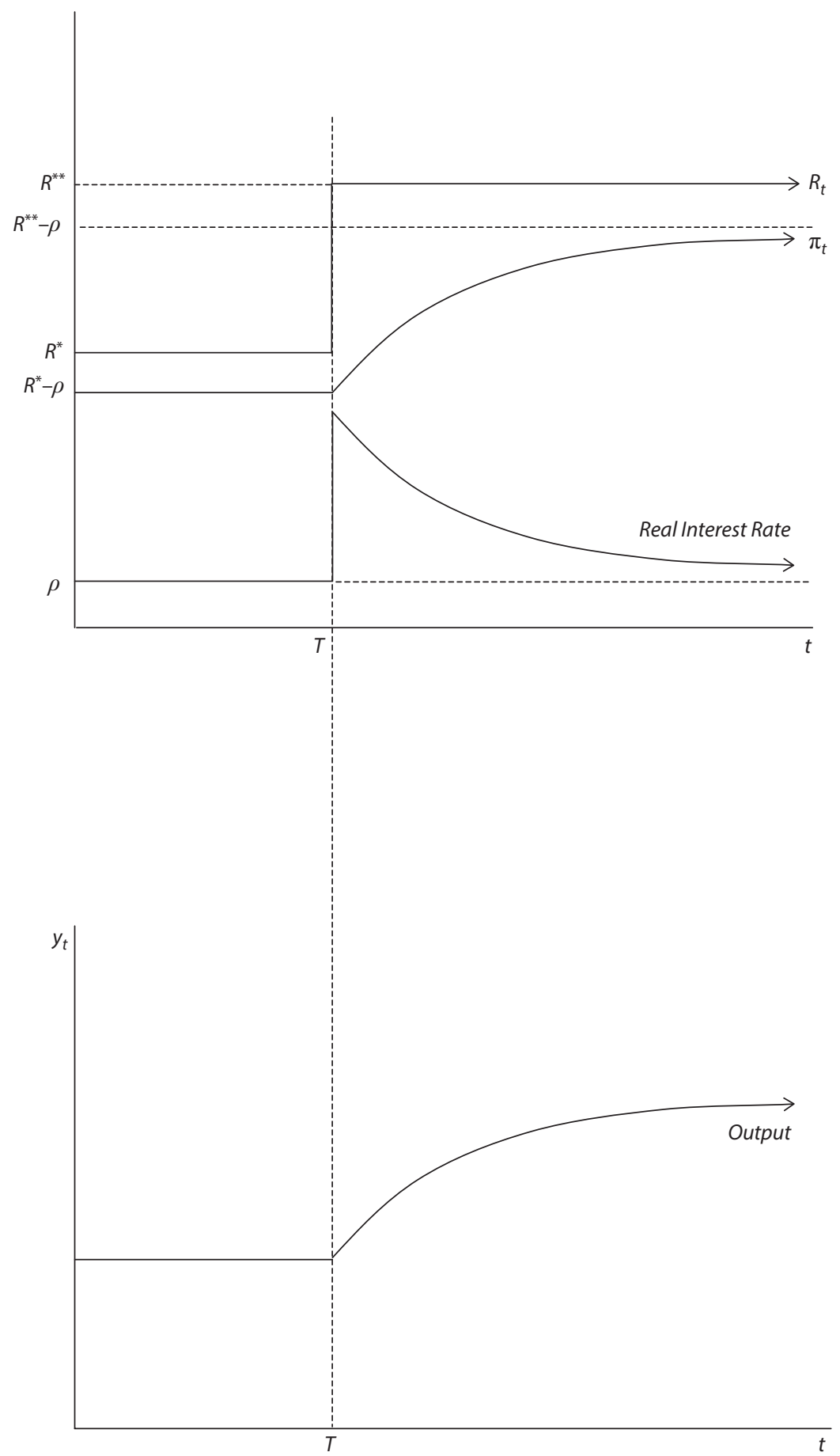


To explore this, consider an experiment in which there is a one-time permanent anticipated increase in the nominal interest rate. In particular, suppose that $R_{t}=R^{*}$ for $t=0,1,2, \ldots, T-1$ and that $R_{t}=R^{* *}$ for $t=T, T+1, T+2, \ldots$, where $R^{* *}>R^{*}$. In terms of our policy rule, this is equivalent to a one-time anticipated increase in the inflation target at $t=T$. But again, we are faced with a problem of multiple equilibria-there are many paths for the inflation rate consistent with this path for the nominal interest rate. One approach, which follows what is done in Cochrane (2016), is to focus on an equilibrium that is at the steady state value up to period $T-1$. That is, $\pi_{t}=R^{*}-\rho$ for $t=0,1,2, \ldots, T-1$. One can justify focusing on this equilibrium by arguing that if $T$ is arbitrarily large, then any equilibrium has the property that $\pi_{T-1}$ is arbitrarily close to $R^{*}-\rho$. Then, the path followed by the inflation rate is shown in Figure 3, where $D_{1}$ is equation (7) when $\pi^{*}=R^{*}-\rho$, and $D_{2}$ is equation (7) when $\pi^{*}=R^{* *}-\rho$. Figure 4 shows the paths followed by the nominal interest rate, the inflation rate, the real interest rate, and real output. Therefore, in this particular equilibrium, the permanent increase in the nominal interest rate leads to an increase in the inflation rate, even in the short run. Inflation and output rise steadily and converge to their long-run values, while the real interest rate rises on impact and then falls.

The following mechanism is at work here. The increase in the nominal interest rate initially increases the real interest rate, and this causes the representative consumer to substitute future spending for current spending. Yet this does not imply a decline in current spending but rather a rise in future spending. Output will be higher in the future and, through the Phillips curve effect, this implies a rise in inflation over time. So inflation actually moves in the opposite direction to what conventional wisdom says. This NK model incorporates all the elements of conventional wisdom, but its predictions run counter to conventional wisdom. These results are not unique to the simplified model analyzed here, as Cochrane (2016) and Rupert and Sustek (2016) come to similar conclusions in more standard quantitative NK models.

But we need to take these results with at least two grains of salt. First, there are multiple equilibria, so Figure 3 does not represent a clean policy experiment. Second, in modern macroeconomics we are interested in the operating characteristics of the economy under particular policy rules, not in the response of economic variables to some hypothetical one-time change in a policy variable. Thus, in the next sections we explore how alternative versions of the Taylor rule (6) matter for the central bank's success in hitting its inflation target.

\section{The Taylor Principle and the Policy Trap}

Taylor (1993) reasoned that the coefficient $\delta$ in equation (6) should satisfy $\delta>1$. Taylor's argument appeared to involve Phillips curve reasoning. That is, if the inflation rate increases by 1 percentage point, then the nominal interest rate should increase by more than 1 percentage point, causing the real interest rate to rise, causing output to fall, by Taylor's logic. Then, through a Phillips curve effect, the decrease in output causes inflation to fall, according to him. The sign restriction $\delta>1$ in the Taylor rule (6) is sometimes called the Taylor principle. In terms of our model, is Taylor right? That is, does the Taylor principle yield good results if the central bank adopts it? As we will show here, in this model Taylor is wrong.

To start, from (3), (5), and (6) we get 
Figure 5

Inflation Dynamics Under the Taylor Principle

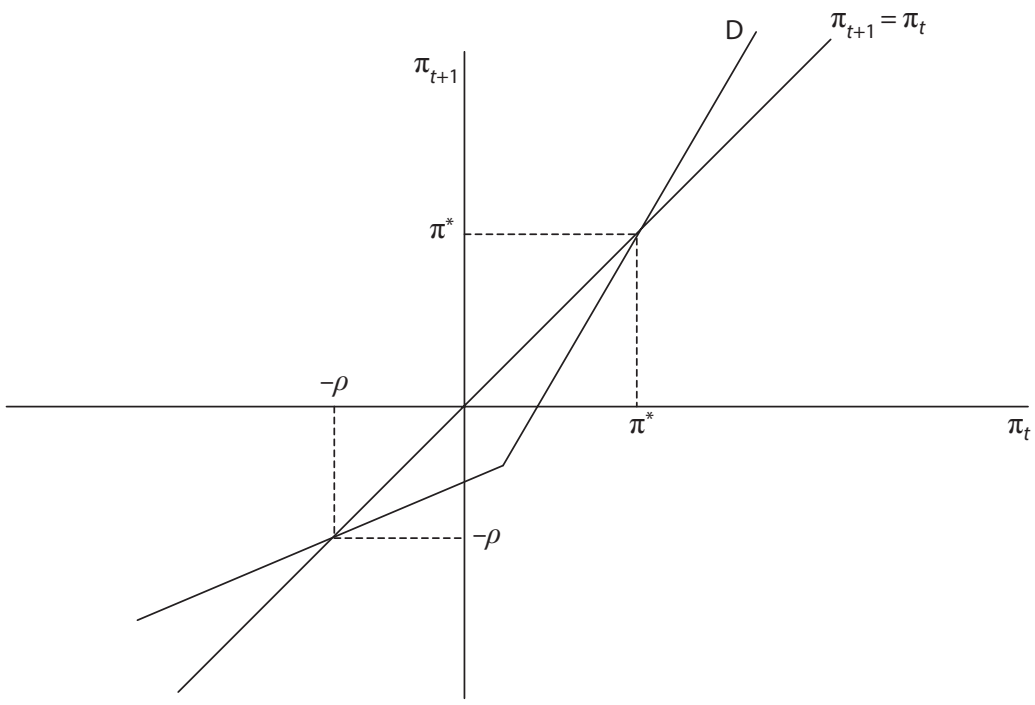

$$
\pi_{t+1}=\max \left[-\frac{\rho \gamma}{\alpha+\gamma}+\frac{\alpha}{\alpha+\gamma} \pi_{t}, \frac{(1-\delta) \gamma}{\alpha+\gamma} \pi^{*}+\frac{\delta \gamma+\alpha}{\alpha+\gamma} \pi_{t}\right] .
$$

If $\delta>1$, then equation (8) is depicted as $D$ in Figure 5. Note that there are two steady states. One is the desired steady state for the central bank, which is $\pi_{t}=\pi^{*}$ for all $t$; that is, the steady state in which the central bank hits its inflation target forever. The second steady state is $\pi_{t}=-\rho$ for all $t$, which implies from (6) that $R_{t}=0$. In this ZLB equilibrium, the central bank perpetually undershoots its inflation target-indeed, there is deflation forever-and the central bank keeps the nominal interest rate at zero in the hope that inflation will eventually go up. But of course it does not.

An interesting feature is that there are many equilibria that converge to the ZLB steady state. Each of these has $\pi_{0}<\pi^{*}$. If $-\rho<\pi_{0}<\pi^{*}$, then the inflation rate falls over time and converges to $-\rho$, whereas if $\pi_{0}<-\rho$, then the inflation rate increases over time and converges to $-\rho$. There are also many hyperinflationary equilibria. If $\pi_{0}>\pi^{*}$, then inflation increases without bound. So the desired steady-state equilibrium with $\pi_{t}=\pi^{*}$ is not stable. This is perhaps surprising, as the Taylor principle is touted in Woodford (2003) as a device for obtaining determinacy in NK models. But Woodford's argument for determinacy relates to local determinacy. That is, in Figure 5, if the initial inflation rate $\pi_{0}$ is close to $\pi^{*}$, then inflation will move away from $\pi^{*}$ over time. Thus, if our criterion is local determinacy in a neighborhood of the steady state $\pi_{t}=\pi^{*}$, we would rule out all equilibria except the desired steady state $\pi_{t}=\pi^{*}$. But for our model, we know more than its behavior close to the desired steady state-we know all the global dynamics - and this tells us something different from Woodford's analysis.

The fact that there are perils of Taylor rules was first pointed out by Benhabib, Schmitt- 
Grohe, and Uribe (2001). The idea is that the Taylor principle creates dynamic forces that lead to perpetual undershooting of a central bank's inflation target. In other words, the central bank gets stuck in a policy trap at the ZLB. These predictions actually provide a good description of the recent behavior of many central banks in the world. And the Bank of Japan was a leader in policy-trap central banking, with Japan having now experienced low inflation and low nominal interest rates for more than 20 years. Since the financial crisis, the Bank of Japan has more company in the low-nominal-interest rate club, including the European Central Bank, the Bank of England, the Swiss National Bank, the Federal Reserve System, the Swedish Riksbank, and the Bank of Canada. In all of these countries, the tendency during prolonged low-nominal-interest-rate periods is for inflation to undershoot inflation targets, which are typically set at 2 percent.

\section{A Neo-Fisherian Policy Rule}

So far, we have shown that some types of monetary policy rules leave something to be desired. First, if the central bank pegs the nominal interest rate forever, then the inflation rate will ultimately converge to the central bank's inflation target, but the inflation rate could be far from the inflation target for a very long time. Second, a central bank following the Taylor principle faces Taylor rule perils. That is, the central bank could become stuck in a policy trap in which inflation is perpetually below the inflation target, with the central bank maintaining the nominal interest rate at the ZLB and facing persistent frustration that inflation is not going up. In addition, a central bank following the Taylor principle could end up on a hyperinflationary path where nominal interest rates and inflation increase forever.

However, there exist alternative monetary policy rules that perform much better. Consider the following rule:

$$
\begin{aligned}
& \text { If } \pi_{t}<\pi^{*} \text {, then } R_{t}=\rho+\frac{\alpha+\gamma}{\gamma} \pi^{*}-\frac{\alpha}{\gamma} \pi_{t} \text {, and } \\
& \text { if } \pi_{t} \geq \pi^{*} \text {, then } R_{t}=\rho-\frac{\alpha}{\gamma} \pi^{*}+\frac{\alpha+\gamma}{\gamma} \pi_{t+1} .
\end{aligned}
$$

This rule states that, if inflation is currently below the inflation target, then according to (9) the central bank should raise the nominal interest rate, which has the effect of bringing the inflation rate back to its target in the following period. However, if inflation is currently above the inflation target, then according to (10) the central bank should increase the nominal interest rate in response to future inflation, which has the effect of bringing current inflation to the target. This latter element of policy effectively prevents high future inflation from feeding back to the present and generating current above-target inflation.

The policy rule (9) and (10) is depicted as $D$ in Figure 6 . The equilibrium implied by this neo-Fisherian rule is $\pi_{0} \leq \pi^{*}$ and $\pi_{t}=\pi^{*}$ for $t \geq 1$; that is, the central bank may miss its inflation target on the low side for one period but then hit the target in each succeeding period. This is a neo-Fisherian rule, as the central bank acts to raise the nominal interest rate both if inflation is too low and to kill off incipient excessive inflation. 
Figure 6

A Neo-Fisherian Monetary Policy Rate

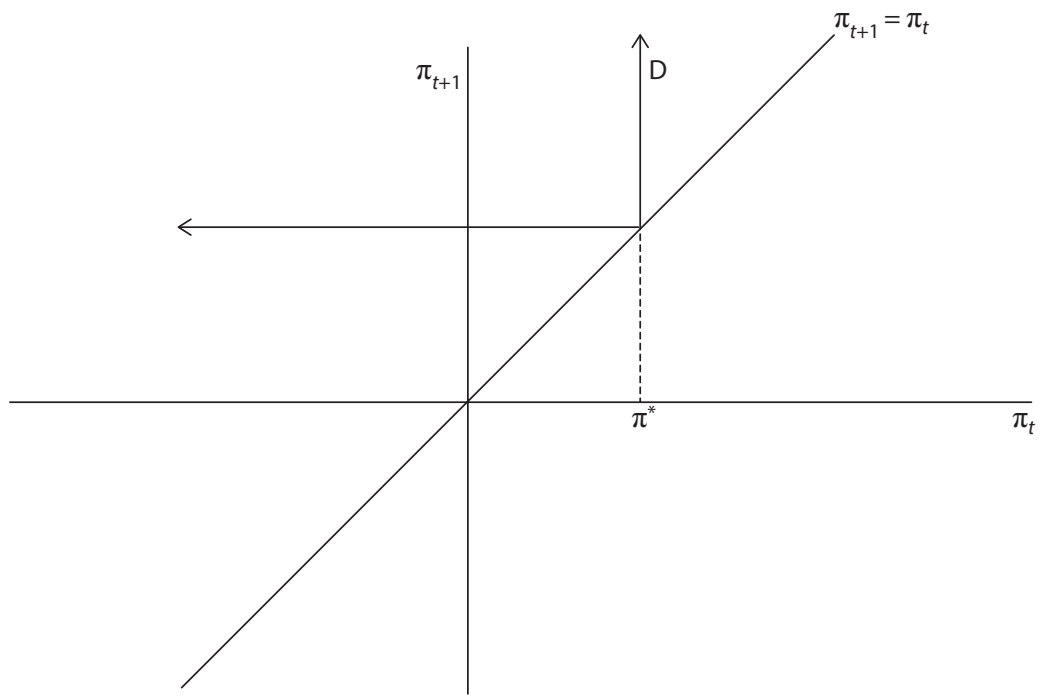

\section{Sticky Expectations}

All of the analysis we have done so far assumes rational expectations. But some policy thinking, and some macroeconomic research, proceeds under the assumption that there exists some form of stickiness in inflation expectations. We want to explore the ramifications of sticky expectations to understand what the proponents of this approach have in mind.

This sticky expectations setup is inspired by Evans and McGough (2017). Assume that the representative consumer has beliefs about future inflation that evolve according to

$$
\hat{\pi}_{t+1}=(1-\omega) \hat{\pi}_{t}+\omega \pi_{t},
$$

where $0 \leq \omega \leq 1$. That is, the period $t$ belief about period $t+1$ inflation, denoted by $\hat{\pi}_{t+1}$, is updated based on the period $t-1$ belief about period $t$ inflation, as well as actual inflation in period $t$. In equation (11), $\omega$ determines the degree of stickiness in inflation expectations, with a lower value of $\omega$ denoting more stickiness.

Using (3), (5), and (11), we can solve for current inflation and for expected inflation in period $t+1$ as functions of expected inflation in period $t$ and the current nominal interest rate:

$$
\begin{aligned}
& \pi_{t}=\frac{(1-\omega)(\alpha+\gamma)}{\alpha-\omega(\alpha+\gamma)} \hat{\pi}_{t}-\frac{\gamma}{\alpha-\omega(\alpha+\gamma)}\left(R_{t}-\rho\right), \\
& \hat{\pi}_{t+1}=\frac{\alpha(1-\omega)}{\alpha-\omega(\alpha+\gamma)} \hat{\pi}_{t}-\frac{\omega \gamma}{\alpha-\omega(\alpha+\gamma)}\left(R_{t}-\rho\right) .
\end{aligned}
$$


Then, given anticipated inflation in the initial period, $\hat{\pi}_{0}$, equations (12) and (13) determine the paths for equilibrium inflation and anticipated inflation.

It is useful to look at extreme cases. First, suppose that $\omega=0$, which implies from (13) that $\hat{\pi}_{t}=\hat{\pi}$, a constant, for all $t$. Then (12) gives

$$
\pi_{t}=\frac{(\alpha+\gamma)}{\alpha} \hat{\pi}-\frac{\gamma}{\alpha}\left(R_{t}-\rho\right)
$$

so current inflation declines if the current nominal interest rate increases. This captures conventional wisdom, which is consistent with standard undergraduate static IS/LM/Phillips curve macroeconomics. If inflation expectations are fixed, then anticipated future output is fixed as well, from the Phillips curve relation. But then an increase in the nominal interest rate increases the real interest rate one-for-one, and this causes the representative consumer to substitute future consumption for current consumption. But future consumption is fixed, so current consumption must fall.

Next, suppose the other extreme, which is $\omega=1$. Then, from (12) and (13) we get

$$
\pi_{t}=\hat{\pi}_{t+1}=R_{t}-\rho
$$

In this case, the representative consumer is myopic, in that he or she expects inflation next period to be the same as it is this period. This implies an extreme Fisherian result. From (15), an increase in the current nominal interest rate leads to a one-for-one increase in the inflation rate and anticipated inflation, which implies that the real interest rate is constant forever, at $\rho$. However, note that from the Phillips curve, equation (5), output moves with inflation. If the nominal interest rate goes up, then inflation and output go up.

It will prove useful to understand the dynamics of inflation and inflation expectations when $R_{t}=0$ for all $t$, which is a permanent ZLB monetary policy. In this case, from (12) and (13),

$$
\begin{aligned}
& \pi_{t}=\frac{(1-\omega)(\alpha+\gamma)}{\alpha-\omega(\alpha+\gamma)} \hat{\pi}_{t}+\frac{\rho \gamma}{\alpha-\omega(\alpha+\gamma)}, \\
& \hat{\pi}_{t+1}=\frac{\alpha(1-\omega)}{\alpha-\omega(\alpha+\gamma)} \hat{\pi}_{t}+\frac{\omega \rho \gamma}{\alpha-\omega(\alpha+\gamma)},
\end{aligned}
$$

where equation (17) determines the path for anticipated inflation $\hat{\pi}_{t}$ and equation (16) determines actual inflation $\pi_{t}$ in each period. There is a unique steady state, $\pi_{t}=\hat{\pi}_{t}=-\rho$, which is deflation at the natural rate of interest.

First, suppose that

$$
\omega<\frac{\alpha}{\alpha+\gamma}
$$

This then implies that the coefficient on $\hat{\pi}_{t}$ in equation (17) is greater than 1 . Therefore, there are many equilibria. If $\hat{\pi}_{0}<-\rho$, then the inflation rate falls forever-there is a deflationary spiral. But if $\hat{\pi}_{0}>-\rho$, then inflation increases forever-a hyperinflation. So if (18) holds, then the steady state $\pi_{t}=\hat{\pi}_{t}=-\rho$ is unstable given the ZLB monetary policy. 
Next, suppose that

$$
\frac{\alpha}{\alpha+\gamma}<\omega<\frac{2 \alpha}{2 \alpha+\gamma}
$$

In this case, the coefficient on $\hat{\pi}_{t}$ in equation (17) is less than -1 . Again, as a result, there are many equilibria. For any $\hat{\pi}_{0} \neq-\rho$ there is an equilibrium that diverges from the steady state and cycles between inflation rates greater than and less than $-\rho$, with the distance from $-\rho$ increasing over time. As in the first case given by (18), the steady state is unstable.

Finally, suppose that

$$
\omega>\frac{\alpha}{\alpha+\gamma}
$$

In equation (17), the coefficient on $\hat{\pi}_{t}$ is less than zero but greater than -1 . This implies that the steady-state equilibrium is stable, but there are many equilibria with arbitrary initial anticipated inflation $\hat{\pi}_{0}$. Inflation cycles to its steady-state value in all of these equilibria.

It can be shown that the Taylor principle runs into some of the same problems as in the rational expectations case, in addition to some new problems. But to cut to the chase, consider a monetary policy rule that will achieve the inflation target given $\hat{\pi}_{t}$, as long as policy is not constrained by the ZLB. This rule is

$$
R_{t}=\max \left[0, \rho-\frac{\alpha-\omega(\alpha+\gamma)}{\gamma} \pi^{*}+\frac{(1-\omega)(\alpha+\gamma)}{\gamma} \hat{\pi}_{t}\right] .
$$

If $R_{t}>0$, then from (21) and (13), we have

$$
\hat{\pi}_{t+1}=(1-\omega) \hat{\pi}_{t}+\omega \pi^{*}
$$

In contrast to the Taylor rule, specified in (6), the nominal interest rate in the policy rule (21) responds to anticipated inflation rather than to actual inflation. This assumes that the central bank can observe anticipated inflation. From (21), note that $R_{t}=0$ if and only if

$$
\hat{\pi}_{t} \leq \tilde{\pi},
$$

where

$$
\tilde{\pi}=-\frac{\rho \gamma}{(1-\omega)(\alpha+\gamma)}+\frac{\alpha-\omega(\alpha+\gamma)}{(1-\omega)(\alpha+\gamma)} \pi^{*}
$$

Given this monetary policy rule, the nominal interest rate exceeds zero only when anticipated inflation exceeds the threshold $\tilde{\pi}$. But from (22), once the nominal interest rate exceeds zero, the central bank will achieve its inflation target from that date on. Therefore, achieving the inflation target will depend on whether the central bank can get inflation expectations above the threshold $\tilde{\pi}$.

A standard monetary policy narrative is that if inflation is below its target, then the central bank can raise inflation by keeping interest rates low for a sufficiently long time. Then, once 
inflation is sufficiently high, the central bank can normalize policy-that is, restore conventional monetary policy rules. Under some circumstances, our sticky expectations model conforms to this standard narrative. In the case in which (18) holds, from (24) we have $-\rho<\tilde{\pi}<\pi^{*}$. Also, from (23), (24), and (16), $\hat{\pi}_{t} \leq \tilde{\pi}$ if and only if $\pi_{t} \leq \pi^{*}$. Given that (18) holds, if $-\rho<\hat{\pi}_{0}<\tilde{\pi}$, then the central bank will see inflation below the inflation target. But with the nominal interest rate at zero, inflation and anticipated inflation increase until inflation exceeds the inflation target; then the nominal interest rate exceeds zero according to the policy rule (21), at which point the central bank achieves its inflation target forever after.

A problem occurs, however, if (18) holds and $\hat{\pi}_{0}<-\rho$. In this case, the central bank maintains a ZLB policy forever, and inflation falls indefinitely. There is a deflationary spiral that the central bank cannot stop.

The behavior of the model is quite different in the case in which (18) does not hold. Then, $\hat{\pi}_{t} \leq \tilde{\pi}$ if and only if $\pi_{t} \geq \pi^{*}$. In this case, following the policy rule (21) implies that the nominal interest rate is zero when the inflation rate is above the central bank's target. Also, if (18) does not hold, then $\tilde{\pi}<-\rho$, which implies that if the central bank follows the policy rule (21), there will be at most one period when the inflation rate is above the central bank's target and the nominal interest rate is zero. Then, the central bank achieves its target either from period $t=0$ on, or from period $t=1 \mathrm{on}$. This behavior does not conform to the standard policy narrative, in that the ZLB policy is not necessary for the central bank to achieve its inflation target.

Inequality (18) will hold when inflation expectations are very sticky ( $\omega$ is small) and when prices are very sticky ( $\gamma$ is small). Thus, it requires sufficient stickiness in inflation expectations and in prices to obtain policy results that conform to the conventional narrative. But even then, the model predicts that equilibria exhibiting perpetually declining inflation can arise. The latter prediction might give us pause, as countries with extended periods of low nominal interest rates have not experienced persistent deflations, let alone deflationary spirals. For example, over the past 22 years, Japan has had very low nominal interest rates and average inflation of close to zero.

\section{SEGMENTED MARKETS: AN ALTERNATIVE MODEL OF LIQUIDITY EFFECTS}

Our results, obtained with a conventional NK model, cast doubt on conventional monetary policy narratives. The model tells us that too-low inflation can be cured through increases in nominal interest rates and that central banks following aggressive Taylor rule policies can find themselves in a policy trap-perpetual low inflation that does not respond to low nominal interest rates.

But perhaps these results are peculiar to NK models? Models with sticky wages and prices are not the only macroeconomic frameworks that have been used to study non-neutralities of money and liquidity effects. Some macroeconomic models that exhibit liquidity effects are segmented markets models, first studied by Grossman and Weiss (1983) and Rotemberg (1984). A particularly simple segmented markets model is the one constructed by Alvarez, Lucas, and Weber (2001), which we will use here with minor modifications. 
There is a continuum of households with unit measure. Traders are a fraction $\lambda$, and non-traders are a fraction $1-\lambda$ of the total population, respectively. Each household maximizes

$$
E_{0} \sum_{t=0}^{\infty}\left(\frac{1}{1+\rho}\right)^{t} u\left(C_{t}^{i}\right)
$$

where $i=T$ if the household is a trader and $i=N$ if the household is a non-trader, with $E_{t}$ denoting the expectation conditional on time $t$ information. In period $t$, each household receives an endowment $y$, which it cannot consume. The endowment is sold on a competitive goods market for cash at price $P_{t}$. The household purchases consumption goods on the competitive goods market with cash acquired in advance. At the beginning of the period, a bond market opens in which the government and trader households participate. Also, suppose the government has access to lump sum taxes and taxes the traders only.

So in each period, the bond market opens, the government issues money and one-period bonds, and it levies taxes subject to its budget constraint. Then the goods market opens, with households purchasing goods subject to cash-in-advance constraints. Following this, households receive the receipts from sales of their endowments and carry assets into the next period. Traders hold a portfolio of cash and government bonds, while non-traders hold only cash. Monetary policy is conducted by the central bank through open market operations-swaps of money for government bonds.

We will consider only cases where cash-in-advance constraints always bind. This makes solving the model mechanical. Because cash-in-advance constraints bind, all cash is spent in the goods market each period, so total nominal expenditures is equal to the total money stock,

$$
P_{t} y=M_{t} \text {, }
$$

where $M_{t}$ is the stock of money in period $t$. The consumption of a trader, in nominal terms, is given by

$$
P_{t} c_{t}^{T}=P_{t-1} y+\frac{M_{t}-M_{t-1}}{\lambda},
$$

where $c_{t}^{T}$ is the real value of consumption for a trader. Equation (27) states that a trader spends the receipts from the previous period's sales of goods, plus whatever money injection occurred through open market operations in the current period. Similarly, a non-trader consumes according to

$$
P_{t} c_{t}^{N}=P_{t-1} y
$$

So the non-trader spends only last period's receipts from sales of goods, as the non-trader does not trade on financial markets.

Solving for a trader's consumption in equilibrium from (26) and (27), we get

$$
c_{t}^{T}=\left(\frac{y}{\lambda}\right)\left(\frac{\lambda+\pi_{t}}{1+\pi_{t}}\right) .
$$


Note here that $\pi_{t}$ is both the inflation rate and the money growth rate from (26). The key feature of this model is the redistributive effect of monetary policy. Higher money growth increases the inflation rate, but it also redistributes wealth from non-traders to traders and increases the consumption of traders.

From (29), note that we require

$$
\pi_{t} \geq-\lambda
$$

to guarantee that consumption is non-negative. That is, if the central bank reduces the money stock, it cannot extract more cash from the economy than what the traders are holding.

To determine the nominal interest rate on a one-period nominal bond that sells for one unit of money in period $t$ and pays off $1+R_{t}$ units of money in period $t+1$, we need only be concerned with the behavior of traders. Optimality, for traders in the bond market, gives

$$
-u^{\prime}\left(c_{t}^{T}\right)+\frac{\left(1+R_{t}\right)}{(1+\rho)} E_{t}\left[\frac{u^{\prime}\left(c_{t+1}^{T}\right)}{\left(1+\pi_{t+1}\right)}\right]=0 .
$$

It is useful to rewrite (31) as

$$
\frac{1}{1+R_{t}}=E_{t}\{\underbrace{\left[\frac{u^{\prime}\left(c_{t+1}^{T}\right)}{(1+\rho) u^{\prime}\left(c_{t}^{T}\right)}\right]}_{\text {Liquidity effect }} \underbrace{\left(\frac{1}{1+\pi_{t+1}}\right)}_{\text {Fisher effect }}\} .
$$

In (32), the nominal interest rate (left-hand side) is determined by two effects (right-hand side). First is the liquidity effect, or the real interest rate effect. From (29), money growth affects consumption, which matters for the real interest rate. In particular, higher current money growth and inflation $\pi_{t}$ increases $c_{t}^{T}$, which reduces $u^{\prime}\left(c_{t}^{T}\right)$, reducing the real interest rate and the nominal interest rate. Also, higher future money growth and inflation $\pi_{t+1}$ increases future consumption, reducing $u^{\prime}\left(c_{t+1}^{T}\right)$ and increasing the real interest rate and the nominal interest rate $R_{t}$. Second, higher future money growth and inflation also have a Fisher effect, over and above the liquidity effect. This effect works in the same direction as the effect of higher future money growth and inflation on the nominal interest rate.

\section{Random Monetary Policy}

Suppose the central bank sets the nominal interest rate $R_{t}$ through appropriate open market operations, reflected in the money growth rate. In particular, assume for the sake of argument that the nominal interest rate is chosen randomly. That is, $R_{t}$ is i.i.d. over time. This then implies that, from (29),

$$
E_{t}\left[\frac{u^{\prime}\left(c_{t+1}^{T}\right)}{\left(1+\pi_{t+1}\right)}\right]=A,
$$

where $A$ is a positive constant. Therefore, from (29) and (31), 


$$
u^{\prime}\left[\left(\frac{y}{\lambda}\right)\left(\frac{\lambda+\pi_{t}}{1+\pi_{t}}\right)\right]=\frac{\left(1+R_{t}\right) A}{1+\rho} .
$$

In equation (33), if the nominal interest rate $R_{t}$ increases, this increases the right-hand side, which implies that current inflation must fall, since the left-hand side of equation (33) is decreasing in $\pi_{t}$. This occurs because the nominal interest rate is an i.i.d. draw, so the current nominal interest rate is not informative about future inflation. Therefore, there can only be a liquidity effect from the current change in monetary policy. As lower current money growth implies a higher current nominal interest rate, through the liquidity effect, the central bank must engineer a temporarily low money growth rate to support a temporarily high nominal interest rate.

If the central bank experiments in this fashion, it will observe inflation and nominal interest rates moving in opposite directions. The central bank might then conclude that if inflation is below the central bank's inflation target, then the way to raise inflation permanently is to lower the nominal interest rate permanently. In the next section, we will show that, as in the NK model, this conclusion is incorrect.

\section{Inflation Dynamics in the Segmented Markets Model}

To explore how inflation responds to monetary policy in the short run and long run in the segmented markets model, it is useful to consider a special case so that we can work out results explicitly. Assume that $u(c)=\log c$ and that the central bank's settings for the nominal interest rate are known in advance, so there is no uncertainty. Then, from (29) and (31),

$$
\pi_{t+1}=-\lambda+\frac{\left(1+R_{t}\right)\left(\lambda+\pi_{t}\right)}{(1+\rho)\left(1+\pi_{t}\right)} .
$$

First, if in (34) $R_{t}=R$, a constant, then there are two steady states, $\pi_{t}=-\lambda$ for all $t$ and $\pi_{t}=\frac{R-\rho}{(1+\rho)}$ for all $t$. So if the central bank sets $R=(1+\rho)\left(1+\pi^{*}\right)-1$, where $\pi^{*}$ is the central bank's inflation target, with $\frac{R-\rho}{(1+\rho)}=\pi^{*}$, there is a desired steady state in which the central bank achieves its inflation goal. We will assume throughout that

$$
\lambda>\frac{\rho}{(1+\rho)},
$$

which implies that the desired steady state is always feasible, given (30). In Figure 7 we depict equation (34) with $R=(1+\rho)\left(1+\pi^{*}\right)-1$. The desired steady state is stable, while the undesired steady state is unstable, with many equilibria that converge to $\pi^{*}$ from both above and below. Therefore, as in the NK model, there may be indeterminacy if the central bank pegs the nominal interest rate, but there is no instability with respect to the inflation target.

In this context, we write the Taylor rule in multiplicative form as

$$
R_{t}=\max \left[0,-1+(1+\rho)\left(1+\pi_{t}\right)^{\delta}\left(1+\pi^{*}\right)^{1-\delta}\right]
$$


Therefore, from (34) and (35) we obtain

$$
\pi_{t+1}=-\lambda+\max \left[\frac{\left(\lambda+\pi_{t}\right)}{(1+\rho)\left(1+\pi_{t}\right)},\left(\lambda+\pi_{t}\right)\left(1+\pi_{t}\right)^{\delta-1}\left(1+\pi^{*}\right)^{1-\delta}\right] .
$$

Solutions to equation (36) are then equilibrium paths for the inflation rate, and we depict equation (36) in Figure 8 for the Taylor principle case with $\delta>1$. There are two steady states, which are $\pi_{t}=-\frac{\rho}{1+\rho}$ for all $t$ and $\pi_{t}=\pi^{*}$; that is, the ZLB equilibrium and the desired steady state in which the central bank achieves its inflation goal. From Figure 8, the ZLB steady state is stable while the desired steady state is not stable, which is the same result we derived for the NK model under the Taylor principle. Just as with the NK model, there are many equilibria that converge to the ZLB steady state, as well as hyperinflationary equilibria for which the inflation rate and the nominal interest rate increase without bound.

We can also derive a neo-Fisherian monetary policy rule for this model, which is

$$
\begin{gathered}
R_{t}=-1+\frac{(1+\rho)\left(\lambda+\pi^{*}\right)\left(1+\pi_{t}\right)}{\left(\lambda+\pi_{t}\right)}, \text { if } \pi_{t}<\pi^{*}, \text { and } \\
R_{t}=-1+\frac{(1+\rho)\left(\lambda+\pi_{t+1}\right)\left(1+\pi^{*}\right)}{\left(\lambda+\pi^{*}\right)}, \text { if } \pi_{t} \geq \pi^{*} .
\end{gathered}
$$

As in the NK model, this rule implies an equilibrium in which the central bank may miss its inflation target on the low side for one period, but it achieves its inflation goal at every succeeding date. The rule states that the central bank should increase the nominal interest rate in response to below-target inflation and raise the nominal interest rate to kill off incipient above-target inflation.

We have analyzed this segmented markets model in nonlinear fashion, as opposed to the linear analysis in the NK model. But the results are essentially the same. In the NK model, the only friction is sticky prices, which implies a liquidity effect and a Phillips curve relationship. In the segmented markets model, the friction is that some economic agents cannot trade on financial markets so that central bank open market operations have distributional effects, which are manifested in a liquidity effect. So these two models are fundamentally quite different, but in terms of inflation dynamics they are almost identical. If the central bank pegs the nominal interest rate then the economy is stable, but there is indeterminacy. If the central bank increases the pegged nominal interest rate, this can lead to a neo-Fisherian effect-the inflation rate increases even in the short run. If the central bank follows the Taylor principle, then this can lead to convergence to a ZLB policy trap in which the central bank perpetually undershoots its inflation target. That is, there exist Taylor rule perils. But if the central bank follows a neo-Fisherian policy rule-increasing the nominal interest rate both when inflation is too low and to fend off incipient above-target inflation-then it does a good job of achieving its inflation goals. 


\section{Figure 7}

Segmented Markets: Pegged Nominal Interest Rate

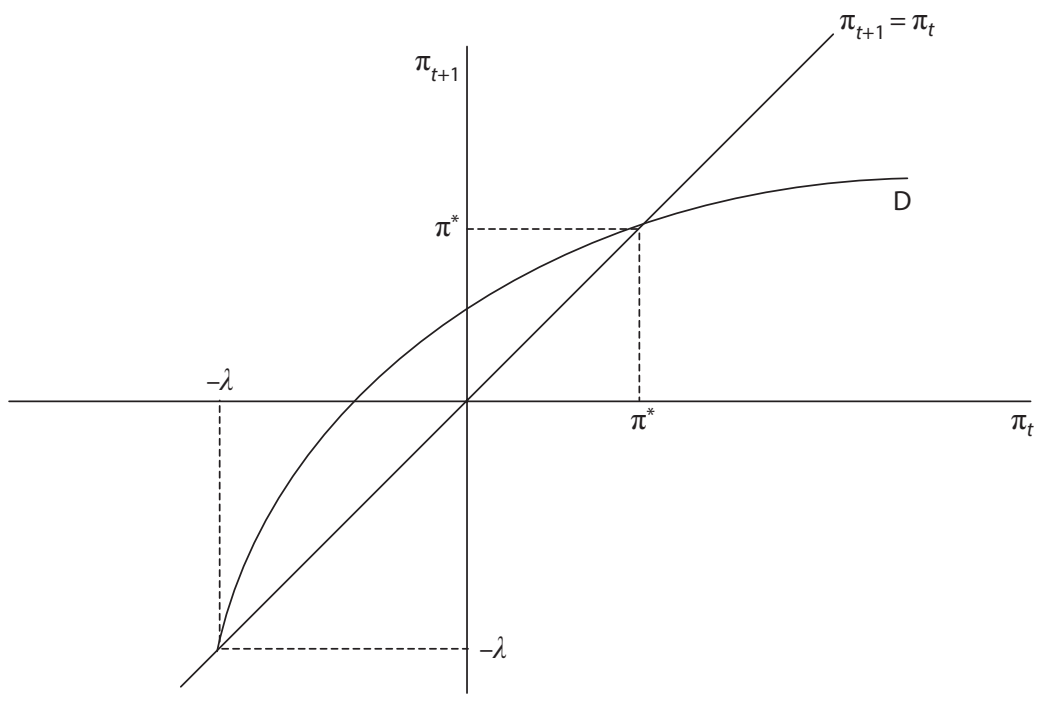

\section{Figure 8}

\section{Segmented Markets: Taylor Principle}

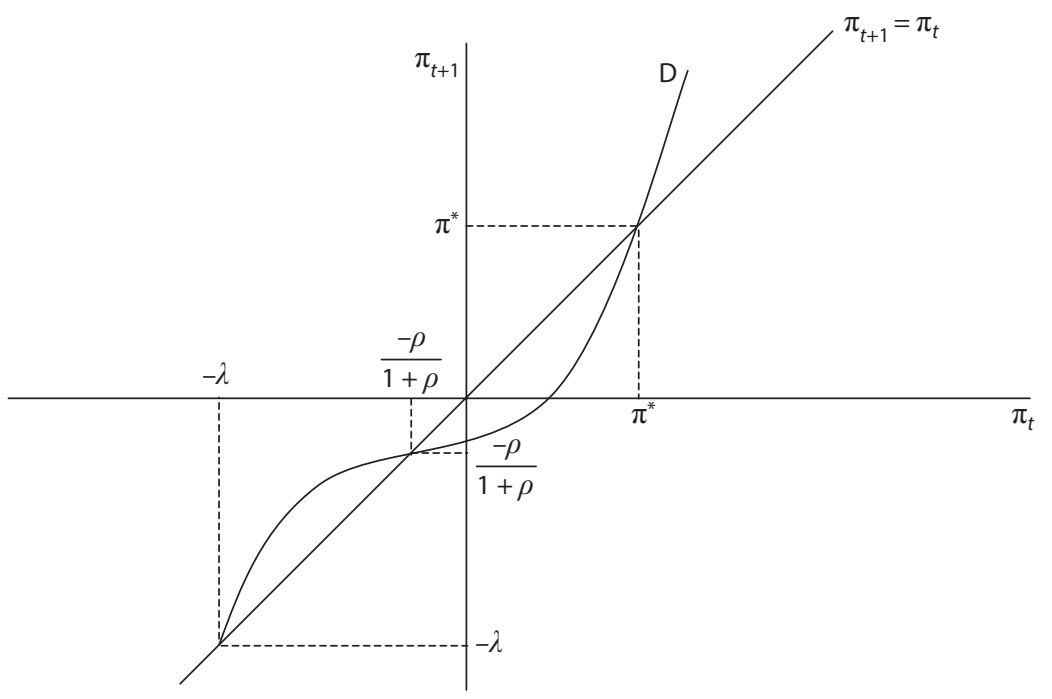




\section{CONCLUSION}

This article has shown how two standard macroeconomic monetary models-a New Keynesian model and a segmented markets model—exhibit neo-Fisherian properties. Central banks following the Taylor principle tend to fall into a low-inflation policy trap, a central bank that raises the nominal interest rate causes inflation to go up (even in the short run), and neo-Fisherian monetary policy rules work well to achieve the central bank's inflation goal. These results summarize some key results from the recent literature on neo-Fisherian macroeconomics and complement what is known empirically about inflation dynamics and monetary policy.

These results are of key importance for monetary policy. They help us understand central bankers' chronic undershooting of the inflation target following the financial crisis, as well as how this problem can be cured. But what are the consequences if central bankers cling to the notion that increases in nominal interest rates make inflation go down? On the one hand, perhaps this is not a serious problem. In a world with very low real interest rates, even with the overnight nominal interest rate at zero, inflation may not fall far below the typical inflation target of 2 percent-a scenario that certainly seems preferable to the persistent high inflation of the 1970s. On the other hand, frustrated central bankers in low-inflation policy traps may be driven to engage in untested unconventional policies, such as quantitative easing, forward guidance, and negative nominal interest rates. These policies may be ineffective, poorly understood by the public (if not by central bankers), and perhaps even harmful.

\section{REFERENCES}

Alvarez, F.; Atkeson, A. and Kehoe, P. "Money, Interest Rates, and Exchange Rates with Endogenously Segmented Markets." Journal of Political Economy, 2002, 110, pp. 73-112; https://doi.org/10.1086/324389.

Alvarez, F.; Lucas, R. and Weber, W. "Interest Rates and Inflation." American Economic Review, 2001, 91, pp. 219-225; https://doi.org/10.1257/aer.91.2.219.

Andolfatto, D. and Williamson, S. "Scarcity of Safe Assets, Inflation, and the Policy Trap." Journal of Monetary Economics, 2015, 73, 70-92; https://doi.org/10.1016/j.jmoneco.2015.03.008.

Bank of Canada. "Monetary Policy." 2017; http://www.bankofcanada.ca/core-functions/monetary-policy/.

Benhabib, J.; Schmitt-Grohe, S. and Uribe, M. "The Perils of Taylor Rules." Journal of Economic Theory, 2001, 96, pp. 40-69; https://doi.org/10.1006/jeth.1999.2585.

Bullard, J. “The Seven Faces of 'The Peril."' Federal Reserve Bank of St. Louis Review, 2010, 92, pp. 339-352; https://files.stlouisfed.org/files/htdocs/publications/review/10/09/Bullard.pdf.

Cochrane, J. “Do Higher Interest Rates Raise or Lower Inflation?" Hoover Institution working paper, 2016.

Cooley, T. Frontiers of Business Cycle Research. Princeton, NJ: Princeton University Press, 1995.

Evans, G. and McGough, B. "Interest Rate Pegs in New Keynesian Models." Forthcoming, Journal of Money, Credit, and Banking, 2017.

Friedman, M. "The Role of Monetary Policy." American Economic Review, 1968, 58, pp. 1-17.

Grossman, S. and Weiss, L. "A Transactions-Based Model of the Monetary Transmission Mechanism." American Economic Review, 1983, 73, pp. 871-880.

Keynes, J.M. A Tract on Monetary Reform. London: MacMillan, 1923. 


\section{Williamson}

Kocherlakota, N. "Fragility of Purely Real Macroeconomic Models." NBER working paper no. 21866, 2016.

Lucas, R. "Liquidity and Interest Rates." Journal of Economic Theory, 1990, 50, pp. 237-264; https://doi.org/10.1016/0022-0531(90)90001-Z.

Prescott, E. "Theory Ahead of Business Cycle Measurement." Federal Reserve Bank of Minneapolis Quarterly Review 1986, 10, pp. 9-22; https://doi.org/10.1016/0167-2231(86)90035-7.

Rotemberg, J. "A Monetary Equilibrium Model with Transactions Costs." Journal of Political Economy, 1984, 92, pp. 40-58; https://doi.org/10.1086/261207.

Rupert, P. and Sustek, R. "On the Mechanics of New Keynesian Models." University of California, Santa Barbara working paper, 2016.

Summers, L. "Less is More When It Comes to Federal Reserve Policy." Financial Times, May 7, 2017; https://www.ft.com/content/ab77d236-318c-11e7-9555-23ef563ecf9a.

Taylor, J. "Discretion Versus Policy Rules in Practice." Carnegie-Rochester Conference Series on Public Policy, 1993, 39, pp. 195-214; https://doi.org/10.1016/0167-2231(93)90009-L.

Tobin, J. "Stabilization Policy Ten Years After." Brookings Papers on Economic Activity, 1980, 11, pp. 19-90; https://doi.org/10.2307/2534285.

Williamson, S. "Neo-Fisherism: A Radical Idea, or the Most Obvious Solution to the Low-Inflation Problem?" Federal Reserve Bank of St. Louis Regional Economist, July 2016, pp. 5-9; https://www.stlouisfed.org/publications/regional-economist/july-2016/neo-fisherism-a-radical-idea-or-themost-obvious-solution-to-the-low-inflation-problem.

Williamson, S. "Low Real Interest Rates and the Zero Lower Bound." Federal Reserve Bank of St. Louis working paper, 2017; https://files.stlouisfed.org/files/htdocs/wp/2017/2017-010.pdf.

Woodford, M. Interest and Prices: Foundations of a Theory of Monetary Policy. Princeton, NJ: Princeton University Press, 2003.

Yellen, J. "The Goals of Monetary Policy and How We Pursue Them." Speech at the Commonwealth Club, San Francisco, CA, 2017; https://www.federalreserve.gov/newsevents/speech/yellen20170118a.htm. 